\title{
REPENSANDO O PAPEL DA JURISDIÇÃO NOS LITÍGIOS ESTRUTURAIS DE INTERESSE PÚBLICO: DO ATIVISMO ANTIDIALÓGICO À DECISÃO COMPARTILHADA ${ }^{1}$
}

\section{RETHINKING THE ROLE OF JURISDICTION IN PUBLIC LAW LITIGATION: FROM THE ANTIDIALOGICAL ACTIVISM TO A SHARED DECISION}

Flavia Danielle Santiago Lima Professora da Universidade de Pernambuco (UPE) e do Programa de Pós-Graduação em Direito (Mestrado) da Faculdade Damas. Mestre e Doutora em Direito Público pela Universidade Federal de Pernambuco/UFPE. Líder do Grupo de Pesquisa JUSPOLÍTICA - Diálogos, Historicidades e Judicialização de Políticas (Direito/UPE). Advogada da União. Recife/PE. E-mail: flavia-santiago@uol.com.br

Eduarda Peixoto da Cunha França Mestranda em Direito pela Universidade Federal de Pernambuco (UFPE). Pesquisadora Bolsista da Coordenação de Aperfeiçoamento de Pessoal de Nível Superior (CAPES). Pesquisadora do grupo JUSPOLÍTICA - Diálogos, Historicidades e Judicialização de Políticas. Bacharel em Direito pela Universidade Católica de Pernambuco (UNICAP). Recife/PE. E-mail: eduardacunhapf@gmail.com

RESUMO: Qual o modelo mais adequado de decisão judicial para litígios estruturais de interesse público? O presente artigo busca responder à questão com a apresentação das discussões teóricas que contemplam aspectos da práxis processual, na descrição dos modelos forte, deferente e compartilhado em casos que envolvem violações sistêmicas a direitos fundamentais. Para tanto, utiliza-se o método dedutivo com pesquisa bibliográfico-

\footnotetext{
${ }^{1}$ Artigo recebido em 09/06/2020 e aprovado em 28/10/2020.
} 
documental de caráter exploratório-descritivo. Conclui-se que o modelo compartilhado, a partir de uma perspectiva normativa, apresenta-se enquanto mais adequado a demandas de caráter estrutural de interesse público. Por outro lado, pelo viés pragmático, observa-se a necessidade de contingência estratégica dos três modelos decisórios, a depender do caso sub judice.

PALAVRAS-CHAVE: Ativismo Judicial; Decisão Compartilhada; Direitos Transindividuais; Processo Estrutural; Políticas Públicas.

ABSTRACT: What is the most appropriate model of judicial decision for structural public interest litigation? This article seeks to answer the question through the normative and pragmatic perspectives, presenting the strong, respectful and shared models in cases involving systemic violations of fundamental rights. For this, the deductive method is used with bibliographic-documentary research of exploratory-descriptive character. It is concluded that the shared model, from a normative perspective, presents itself as more appropriate to demands of a structural nature of public interest. On the other hand, due to the pragmatic bias, there is a need for strategic contingency for the three decision models, depending on the case under judgment.

KEY WORDS: Judicial Activism; Shared Decision-Making; Transindividual Rights; Public Interest Litigation; Public Policy.

\section{Introdução}

Não é raro que casos com alta carga de complexidade e conflituosidade - cujas pretensões exercem tensões sobre interesses múltiplos e excedem demasiadamente os limites da lide - sejam tratados judicialmente de maneira imprópria, a partir de uma ótica que ignora seu contexto e suas intrincadas consequências nos campos econômico, político e social. A judicialização de demandas que envolvem o desenho, a implementação ou até mesmo a correção de políticas públicas, em geral, são exemplos clássicos dessa problemática. 
Não obstante o arranjo estatal clássico atribuir aos membros do Poder Legislativo o estabelecimento dos objetivos que devem ser cumpridos em uma determinada política pública e ao Poder Executivo, em geral, a definição dos instrumentos para o alcance daqueles $^{2}$, frequentemente, o Poder Judiciário, diante de quadros de violações massivas, generalizadas e sistemáticas a direitos fundamentais, provenientes de ações e/ou omissões do próprio Poder Público, decide questões como se individuais fossem, sem que seja desenvolvida alguma medida para quebrar com o ciclo vicioso de falhas estruturais ou que se trate, efetivamente, a fonte do problema.

Visando, a partir das perspectivas normativa e pragmática ${ }^{3}$, responder à pergunta: qual é o modelo mais adequado de decisão judicial para litígios estruturais de interesse público $?^{4}$, o presente trabalho será dividido em três partes. A primeira se debruçará sobre o paradigma das decisões judiciais individuais, que, não raramente, tratam de questões referentes à saúde, moradia, meio-ambiente, sistema público de educação e tantos outros cuja situação diz respeito a problemas com alta carga de complexidade. Discute-se o fato de que ações policêntricas ${ }^{5}$ estão sendo tratadas no campo individual, e não coletivo, fazendo com que problemas sistêmicos sejam conformados no processo judicial como individual, partindo de uma visão micro, que nada contribui para com a cessação da violação reiterada aos direitos em questão.

A segunda parte, por sua vez, apresentará as características gerais dos processos estruturais, a fim de verificar sua aptidão enquanto instrumento para intervenção judicial em

\footnotetext{
${ }^{2}$ DIAS, Jean Carlos. O controle judicial de políticas públicas. Salvador: Juspodium, 2016, p.50.

${ }^{3}$ O termo "pragmático" adotado no presente estudo não faz referência à corrente filosófica do pragmatismo, mas, tão somente a uma perspectiva realística do contexto nas quais as decisões judiciais poderão estar inseridas. Utiliza-se, dessa forma, o sentido trivial da expressão, sem adentrar em conceitos mais específicos do mesmo.

${ }^{4}$ A denominação "litígios estruturais de interesse público" parte do pressuposto de que nem todos os litígios estruturais são, de fato, de interesse público. O recorte do presente artigo, todavia, restringe-se àqueles que são. Sobre a diferenciação de conceitos, ver: LIMA, Edilson Vitorelli Diniz. Levando os conceitos a sério: processo estrutural, processo coletivo, processo estratégico e suas diferenças. Revista de Processo, v. 284, n. 28, p. 333369, jan. 2018. Em suma, entende-se que nem todos os litígios estruturais envolvem o interesse público, da mesma forma que nem todos os litígios de interesse público são estruturais. A nomenclatura aqui adotada, dessa forma, justifica-se no caso do recorte utilizado pelo artigo serem os litígios de caráter estrutural que necessariamente envolvem o interesse público. DIDIER JR, Fredie; ZANETI JR, Hermes; DE OLIVEIRA, Rafael Alexandria. Elementos para uma teoria do processo estrutural aplicada ao processo civil brasileiro. Revista de Processo, v. 303, n. 2020, p. 45-81, 2020, p.48.

${ }^{5}$ FULLER, Lon. The forms and limits of adjudication. Harvard Law Review, v. 92, n. 2, p. 353-409, 1978, p.394.
} 
litígios que envolvam questões de interesse público. Abordará o caso de "Brown v. Board of Education", com o intuito de demonstrar como a Suprema Corte norte-americana enfrentou a doutrina do "separados mas iguais" (separate but equal) e como surgiram, de fato, as chamadas "medidas estruturantes".

Por fim, discutirá quais respostas o Poder Judiciário pode oferecer através da análise de modelos decisórios que foram aqui denominados de "forte" - aqueles nos quais o juiz age de forma mais incisiva a fim de garantir o cumprimento das medidas estruturantes e acaba por diminuir a margem de discricionariedade da Administração pública, do Poder legislativo e dos demais atores envolvidos no litígio (tais como, por exemplo, o Ministério Público e a Defensoria Pública), bem como da sociedade civil - ; o modelo "deferente" - no qual o juiz adota uma postura mais autocontida e, consequentemente, age com deferência às escolhas das instâncias majoritárias e à autocomposição espontânea entre os envolvidos no processo; e, por fim, apresenta-se o modelo intitulado de "compartilhado", no qual o magistrado engaja-se num colóquio contínuo com as demais instituições (públicas e privadas), bem como com a sociedade civil ou o grupo afetado. Enquanto exemplos ilustrativos dos referidos modelos, serão apresentados, respectivamente, os casos: Pugh v. Locke, Holt v. Sarver e Mendoza, Beatriz y ots. c/ Estando Nacional y ots, tendo os dois primeiros ocorrido nos Estados Unidos e o último na Argentina 6 .

O estudo justifica-se pelo fato de que a intervenção judicial no controle de políticas públicas é uma realidade nos tribunais brasileiros ${ }^{7} \mathrm{e}$, consequentemente, faz-se interessante contribuir com bases teóricas adequadas ao referido mister, com o intuito de assegurar a maximização da capacidade institucional dos magistrados e a viabilidade e responsabilidade prática das decisões dos mesmos. A pesquisa não se destina, dessa forma, a discutir se as intervenções judiciais deveriam ou não acontecer - pois assume-se que elas já acontecem ${ }^{8}$ -

\footnotetext{
${ }^{6}$ Os casos foram escolhidos em detrimento do modus operandi das cortes locais serem semelhantes aos modelos que o presente estudo propõe. Destaca-se, ainda, que a apresentação dos casos tem cunho elucidativo e exemplificativo, não sendo suficiente para caracterizar o presente artigo enquanto um "estudo de caso", técnica que demanda abordagens mais específicas e detalhadas. A respeito disso, ver: MACHADO, Maíra Rocha. O estudo de caso na pesquisa em direito. In: MACHADO, Maíra (org). Pesquisar empiricamente o direito. São Paulo: Rede de Estudos Empíricos em Direito, p. 356-390, 2017.

7 ARENHART, Sérgio Cruz. Processos estruturais no direito brasileiro: reflexões a partir do caso da ACP do carvão. Revista de Processo Comparado, v.1, p.211-229, jul./dez, 2015, p.213.

${ }^{8}$ GAURI, Varun; BRINKS Daniel. A new policy landscape: legalizing social and economic rights in the Developing World. In: GAURI, Varun; BRINKS, Daniel (Org). Courting social justice: judicial enforcement of social and economic rights in the developing world. New York: Cambridge University Press, 2000, v.1,
} 
, mas, tão somente, a apresentar como (e se) as objeções que versam sobre a falta de legitimidade democrática e expertise $e^{9}$ podem ser mitigadas em um determinado modelo decisório para o enfrentamento de litígios estruturais de interesse público.

\section{O paradigma das decisões individuais}

Um dos marcos teóricos na temática dos litígios de interesse público é Abraham Chayes, que na obra "The role of judge in public law litigation", identificou cinco características de "concepções tradicionais de adjudicação". São elas: a) bipolarização; b) preocupação retrospectiva; c) interdependência entre direito e remédio; d) atuação episódica; e e) controle das partes sobre o processo. Embora seus estudos dirijam-se ao sistema jurídico norte-americano, os aspectos destacados apresentam correspondência, em grande medida, com a estrutura adjudicatória do ordenamento pátrio.

Uma ação civil, a priori, é tida como uma controvérsia privada entre autor e réu, de forma que a arquitetura jurídica é formulada a partir de dois interesses unitários, diametralmente opostos, a serem decididos a partir de uma lógica na qual "o vencedor leva tudo" ${ }^{10}$. Não obstante a existência da possibilidade de terceiros interferirem no processo a fim de protegerem seus interesses, tais intercessões são uma verdadeira exceção à regra, tratadas pelas cortes e partes como algo, até mesmo, indesejado ${ }^{11}$. A base desse modelo refere-se às perspectivas individualistas ${ }^{12}$ e patrimonialistas, na qual vigoram os princípios da liberdade, propriedade privada e segurança jurídica ${ }^{13}$, entendendo o procedimento civil

\footnotetext{
p.303-354, p.303.

${ }^{9}$ LIMA, Flavia Danielle Santiago; FRANÇA, Eduarda Peixoto da Cunha. Ativismo dialógico x bloqueios institucionais: limites e possibilidades do controle jurisdicional de políticas públicas a partir da Sentencia T025/04 da Corte Colombiana. Argumenta Journal Law, n. 31, p. 209-243, jul./dez., 2019, p.214-215.

10 CHAYES, Abram. The Role of the Judge in Public Law Litigation. Harvard Law Review, v. 89, n. 7, p. 1.281-1.316, mai. 1976, p.1282.

11 PICOLI, Bruno de Lima. Processo estrutural. Dissertação de Mestrado. Curitiba: Universidade Federal do Paraná, 2018, p.75.

12 NUNES, Leonardo Silva; COSTA, Samuel Paiva; FARIA, Ana Maria Damasceno de Carvalho. Dos litígios aos processos estruturais: pressupostos e fundamentos. In: Juliana Cordeiro de Faria Ester Camila Gomes Norato Rezende Edgard Audomar Marx Neto (org.). Novas tendências, diálogos entre direito material e processo. Belo Horizonte: Editora D’Plácido, p.365-383, 2018, p.366.

13 MITIDIERO, Daniel. O processualismo e a formação do Código Buzaid. Revista de Processo. Vol. 183, p. 165-194, maio.2010, p.182.
} 
como mero assunto privado entre as partes ${ }^{1415}$.

A adjudicação, dessa forma, é pensada com o intuito de administração e disposição de patrimônio individual, apartada da tutela de ordem social e metaindividual ${ }^{16}$.

Ao se tratar de uma demanda que envolve políticas públicas, entretanto, adentra-se no risco de ignorar os interesses adjacentes (de terceiros e do próprio Estado, visualizado numa estrutura unitária) e criar consideráveis contradições entre diversas decisões. Ainda que se trate de uma demanda coletiva, é necessário que ela não seja uma mera declaração da "vitória" de uma coletividade vencedora em face do Estado, a fim de que haja uma efetiva tutela dos direitos provenientes de litígios estruturais de interesse público.

Litígios frequentes nas instâncias judiciais brasileiras, respaldadas na legislação material e nas normas processuais, como as milhares de demandas para concessão de medicamentos e disponibilização de leitos hospitalares pelo Sistema Único de Saúde $(\mathrm{SUS})^{17}$, que muitas vezes criam ou exacerbam problemas já presentes, mostram a necessidade de buscar alternativas ao o arquétipo adjudicatório de cariz individual. Demandas que envolvem políticas públicas, em geral, em nada correspondem a um interesse meramente particular.

\subsection{Dos litígios individuais às medidas estruturantes}

No modelo de processo bipolar, a tutela individual de direitos prepondera. Tal solução, todavia, podem agravar o problema, seja porque, para guardar a qualidade das

\footnotetext{
${ }^{14}$ PICOLI, Bruno de Lima. Processo estrutural. Dissertação de Mestrado. Curitiba: Universidade Federal do Paraná, 2018, p.77.

15 "Imprescindível relatar que o direito processual brasileiro data de uma época em que foi organizado para resolver pretensões com estrutura binária. A ideia de processo civil que o Código Buzaid admite gira em torno de dois extremos: o vitorioso e o perdedor da relação processual" DALLA, Humberto; CÔRTES, Victor Augusto Passos Villani. As medidas estruturantes e a efetividade das decisões judiciais no ordenamento jurídico brasileiro. Revista Eletrônica de Direito Processual, v. 13, n. 13, p.229-258, 2014, p.232.

16 MITIDIERO, Daniel. O processualismo e a formação do Código Buzaid. Revista de Processo. Vol. 183, p. 165-194, maio.2010, p.184.

${ }^{17}$ Barroso, ao tratar sobre a judicialização de políticas públicas e suas falhas argumenta que: “ exemplo emblemático nessa matéria tem sido o setor de saúde. Ao lado de intervenções necessárias e meritórias, tem havido uma profusão de decisões extravagantes ou emocionais em matéria de medicamentos e terapias, que põem em risco a própria continuidade das políticas públicas de saúde, desorganizando a atividade administrativa e comprometendo a alocação dos escassos recursos públicos" BARROSO, Luís Roberto. Constituição, democracia e supremacia judicial: direito e política no Brasil contemporâneo. Revista jurídica da presidência, v. 12, n. 96, p. 5-43, 2010, p.13.
} 
decisões não será possível a análise de todas as controvérsias ou porque, para dar conta das demandas, a prestação jurisdicional pode ser sacrificada qualitativamente ${ }^{18}$. A via individual pode ser excludente: quanto maior for a hipossuficiência cultural e econômica do sujeito, menores são as probabilidades que ele tenha acesso à justiça.

$\mathrm{O}$ crescimento exponencial de demandas individuais ${ }^{19}$ impõe a adoção de medidas voltadas à quantidade ao invés de qualidade, enorme investimento estatal para viabilizar a prestação jurisdicional, culminando num infinito ciclo problemas, decorrentes da incapacidade de acompanhar as constantes exigências sociais ${ }^{20}$. Por fim, destaca-se que a intensa judicialização individual pode gerar decisões judiciais contrastantes, insegurança jurídica e elevados custos financeiros e organizacionais.

Demandas individuais tendem a tentar transformar um problema grave em uma discussão singela, como, por exemplo "o direito à saúde pode ou não impor a prestação de um tratamento específico a um determinado indivíduo?”. Nesse caso, limita-se a lide a aparente conflito entre o direito fundamental à vida (e não à saúde) versus o interesse patrimonial do Estado (que se nega a custear o remédio para o autor). Visto dessa perspectiva, a discussão mascara o real problema: a política pública de saúde nacional, disfarçando o fato de que aquilo que está em jogo, de fato, é o debate sobre como devem ser distribuídos os recursos reservados à saúde no país ${ }^{21}$.

A tomada de medidas paliativas e particularizadas, voltadas às consequências de violações estruturais, seriam incapazes de combater as verdadeiras causas do problema. Deste modo, embora o judiciário não seja o locus próprio para o desenho e implementação de políticas públicas, a função jurisdicional tem o dever de, nas lides, viabilizar a

18 ARENHART, Sérgio Cruz. A tutela coletiva de interesses individuais: para além da proteção dos interesses individuais homogêneos. 2. ed. São Paulo: Revista dos Tribunais, 2014, p.150-151.

19 "Na verdade, é inútil inflar a estrutura judiciária, na tentativa de acompanhar o crescimento geométrico da demanda por justiça, na medida em que essa estratégia leva, ao fim e ao cabo, a oferecer mais do mesmo (mais processos - mais crescimento físico da máquina judiciária), pondo em risco o equilíbrio com os demais Poderes e minando a desejável convivência harmoniosa entre eles: com o Executivo, assoberbado com as incessantes requisições de verbas orçamentárias para o crescente custeio da justiça estatal; com o Legislativo, acuado ante a diminuição de seu espaço institucional, por conta dos avanços do ativismo judiciário em áreas tradicionalmente reservadas à chamada reserva legal" MANCUSO, Rodolfo de Camargo. A resolução dos conflitos e a função judicial no contemporâneo Estado de Direito. São Paulo: Revista dos Tribunais, 2009, p. 27.

20 PICOLI, Bruno de Lima. Processo estrutural. Dissertação de Mestrado. Curitiba: Universidade Federal do Paraná, 2018, p.77.

${ }^{21}$ ARENHART, Sérgio Cruz. Processos estruturais no direito brasileiro: reflexões a partir do caso da ACP do carvão. Revista de Processo Comparado, v.1, p.211-229, jul./dez, 2015, p.212. 
concretização de direitos fundamentais ${ }^{22}$.

\subsection{Brown v. Board of Education e o surgimento das "medidas estruturantes"}

Enquanto gênero de litígio constitucional, a reforma estrutural tem suas raízes nos anos 50/60 do século passado, quando a Suprema Corte dos Estados Unidos estava sob a presidência do Chief Justice Earl Warren e realizou-se um esforço considerável para executar a decisão de Brown v. Board of Education. A partir do caso mencionado é que o Judiciário norte-americano assumiu a tarefa de impor a reforma estrutural de várias instituições sociais, o que exigiu das cortes estaduais (em Brown II) uma transformação radical do status quo e da realidade social, pois tiveram que superar uma intensa resistência e, concomitantemente, reestruturar organizações de grande porte, os sistemas de educação pública. A finalidade das medidas adotadas era assegurar os direitos civis, numa perspectiva de igualdade formal, inaugurando a famosa era dos direitos civis "the civil rights era".

Brown era um caso de interesse público cujo pleito central se voltava à cessação da segregação étnica nas escolas públicas do país, em larga medida autorizada pela doutrina do “separados, porém iguais" (separate but equal), sustentada pela Suprema Corte em 1896 no caso "Plessy v. Ferguson" 23 . É certo que a superação de uma doutrina enraizada na cultura do país não seria simples e demandaria uma série de medidas a serem realizadas a longo prazo, bem como a reestruturação do sistema público de ensino como um todo.

Em 1954, dessa forma, a questão da segregação racial foi novamente levada à Suprema Corte Norte-Americana, através do já mencionado caso Brown. Na oportunidade, o julgamento levou à conclusão de que a admissão de estudantes em escolas públicas do país com base na etnia, segregando afrodescendentes, seria inconstitucional. Diante da declaração de inconstitucionalidade, um problema recorrente surgiu no caso: se as escolas públicas estavam, até então, estruturadas a partir do sistema segregacionista, como fazer com que elas adequassem-se ao mandamento constitucional? Afinal, se a tutela do direito material é o fim

\footnotetext{
${ }^{22}$ PICOLI, Bruno de Lima. Processo estrutural. Dissertação de Mestrado. Curitiba: Universidade Federal do Paraná, 2018, p.77.

23 JOBIM, Marcos Félix; ROCHA, Marcelo Hugo. Medidas estruturantes: origem em Brown v. Board of Education. In: ARENHART, Sérgio Cruz; JOBIM, Marco Félix (org.). Processos estruturais. Salvador: JusPodivm, 2017, p.563-582, p.570.
} 
último do processo, não seria suficiente a mera "declaração"24. Seria necessário tornar concreta a medida.

Nesse sentido, a complexidade da decisão de Brown era enorme. Sua efetividade dependia diretamente da mudança de hábitos, pensamentos, cultura e modus operandi de toda uma sociedade, o que demanda tempo. Brown exigia nada menos que a transformação dos "sistemas duais de escolas" com escolas separadas para negros e para brancos em "sistemas unitários de escolas não-raciais", o que denotava a inadiabilidade de uma reforma organizacional profunda. Em outros termos, essa mudança implicaria em novos procedimentos para a escolha de alunos; novos critérios para a construção de escolas; a substituição dos corpos docentes; a revisão do sistema de transportes para acomodar novas rotas e novas distâncias; nova alocação de recursos entre escolas e atividades; a modificação do currículo; o aumento de verbas; a revisão de programas desportivos das escolas; novos sistemas de informação para monitorar o desempenho da organização etc ${ }^{25}$.

O fim da segregação social era um processo de transformação total, no qual os juízes teriam que assumir um papel importante na reconstrução de uma instituição social existente. A erradicação do lema "separate but equal" exigia uma revisão de concepções formadas sobre a estrutura de partes, novas normas de controle do comportamento judicial e novas maneiras de observar a relação entre direito e medidas judiciais. De início, não existia um projeto detalhado sobre como erradicar as iniquidades no acesso aos serviços estatais ou sobre a necessidade de transformar o modo de prestação judicial. Um ano depois da primeira decisão, após diversas queixas de instituições públicas acerca das dificuldades operacionais para implementar a política de não-discriminação, a Suprema Corte voltou a examinar a questão em Brown v. Board of Education II.

Na ocasião, observada a resistência de diversos estados em atender à reforma de suas estruturas, determinou-se a implementação de ordens não-segregativas através da adoção progressiva de medidas eliminatórias das disfunções institucionais ${ }^{26}$. Essas medidas deveriam ser expressas em planos de ação, cuja execução deveria ser acompanhada pelo

\footnotetext{
${ }^{24}$ PICOLI, Bruno de Lima. Processo estrutural. Dissertação de Mestrado. Curitiba: Universidade Federal do Paraná, 2018, p.80.

${ }^{25}$ FISS, Owen. The Forms of Justice. Harvard Law Review, v. 93, p. 1-58, 1979, p. 48.

${ }^{26}$ ARENHART, Sérgio Cruz. A tutela coletiva de interesses individuais: para além da proteção dos interesses individuais homogêneos. 2. ed. São Paulo: Revista dos Tribunais, 2014, p.372.
} 
Poder Judiciário local, de forma a viabilizar a aderência às peculiaridades de cada região.

Após receberem da Suprema Corte ordens para agirem, os juízes federais das instâncias inferiores compreenderam a complexidade da tarefa e ajustaram as formas de procedimentos tradicionais para atender às necessidades existentes ${ }^{27}$.

Essa prática foi considerada por muitos como o ponto inicial das medidas de caráter estruturante, tendo influenciado decisões estruturais voltadas a sistemas prisionais, moradias populares, departamentos de política, entre outros. Dessa forma, além de ampliar o debate acerca da segregação racial, o caso confrontou o modelo tradicional de adjudicação e suas "respostas" às demandas. Como destaca Owen Fiss, a efetivação da medida impôs a revisão das concepções estabelecidas acerca do processo em sua formação tradicional, pois a partir da decisão experimentou-se, no ordenamento norte-americano, uma nova forma de adjudicação : o modelo de structural reform - entendido, no presente estudo, como aquele no qual, por meio da atuação jurisdicional, pretende-se a reorganização e/ou reestruturação de uma instituição (pública ou privada), que causa, fomenta ou viabiliza a ocorrência de um estado de coisas que viola direitos fundamentais através de ações ou omissões ${ }^{28}$ - da qual pode-se extrair algumas valiosas lições ${ }^{29}$.

Em meados dos anos 70, todavia, na Burguer Court, a possibilidade do Judiciário realizar reformas estruturais foi consideravelmente reduzida ${ }^{30}$. O referido período trouxe à

\footnotetext{
27 Susan Sturm destaca - pautando-se na experiência norte-americana - que as mudanças mais significativas nas reformas estruturais acontecem nas instâncias inferiores ao invés de na Suprema Corte do país. STURM, Susan. The legacy and future of corrections litigation. University of Pennsylvania Law Review, v.142, n.2, p.641-735, dez.1993, p.656.

${ }^{28}$ Adota-se, aqui, um conceito similar ao de Edilson Vitorelli ao tratar dos processos estruturais, com algumas modificações, sobretudo tendo em vista o caráter necessariamente público dos litígios aos quais o presente trabalho propõe modelos de decisão judicial. LIMA, Edilson Vitorelli Diniz. Levando os conceitos a sério: processo estrutural, processo coletivo,processo estratégico e suas diferenças. Revista de Processo, v. 284, n. 28, p. 333-369, jan. 2018, p.8.

${ }^{29}$ FISS, Owen. The Forms of Justice. Harvard Law Review, v. 93, p. 1-58, 1979, p. 20.

30 "Por volta dos meados e final dos anos 70, contudo, a Suprema Corte tinha uma nova composição, liderada por Warren Burguer, o Juiz-Presidente ; um forte bloco de juízes, algumas vezes obtendo apoio interno na Corte, procurou reverter os processos que ainda tramitavam em instâncias de grau inferior. Ironicamente, o maior ataque ocorreu em casos de segregação de meados dos anos 70. Em outros casos, em áreas de conflito racial, entre outras, a linha das decisões foi variada: em um caso policial a Burguer Court criticou severamente a reforma estrutural; em um caso de prisão deu-lhe, todavia, grande apoio; e assim por diante. Na maioria das vezes, a Corte ficava bastante dividida; mesmo quando a reforma estrutural sobreviveu, ainda havia divergência marcantes. O contra-ataque da Burguer Court - que enfraqueceu os posicionamentos anteriores - não fechou as portas para a reforma estrutural, mas mudou nossa visão. Durante a era da Warren Court, as inovações procedimentais implícitas na reforma estrutural eram quase imperceptíveis. Os avanços eram pequenos e incrementais; tudo parecia inquestionavelmente correto. Agora isso é passado e temos um entendimento bastante claro dos anos 60 . O mencionado contra-ataque trouxe à luz as mudanças na adjudicação que
} 
baila uma necessidade que permanece até os dias atuais, qual seja, a de examinar a legitimidade - bem como os limites e possibilidades - da intervenção judicial em reformas estruturais, de forma que a oscilação de posturas extremas do Tribunal entre os períodos de ápice e queda das mesmas foi importante na conscientização de que mudanças substanciais não podem depender somente do Judiciário. A reforma estrutural coloca as cortes na posição de emitir diretivas para os demais órgãos estatais ${ }^{31}$, o que não significa, automaticamente, que elas possuem o monopólio da interpretação constitucional ou que estejam em uma posição privilegiada em detrimento do Executivo e Legislativo.

Nesse sentido, uma lição que pode ser tirada do caso é que a adequada tutela de um direito expresso em um litígio estrutural de interesse público não se limita a uma atuação episódica, demarcada no tempo e no espaço. Demanda, outrossim, que haja uma constante relação entre o Judiciário e as instituições sociais. Isso porque esse tipo de demanda não é sustentado por uma simples sanção, mas sim por uma relação que se desenvolverá a longo prazo entre o juiz e os demais atores envolvidos na demanda.

A necessidade de intervenção judicial em casos de reforma estrutural ocorre, sobretudo, pelo fato desses casos envolverem burocracias nas quais a política é determinada por jogos internos de poder e os juízes, nesse sentido, gozam de alguma independência, exercendo importante função - ainda que circunstancialmente limitada ${ }^{32}$ - em casos estruturais que demandam a atribuição de significado a direito fundamental. As reformas estruturais de interesse público, como qualquer outra forma de litígio constitucional, não exigem que as cortes tenham a única ou "última palavra", mas que possam se pronunciar e o façam com certa autoridade, a fim de pôr em marcha medidas capazes de, quando necessário, desbloquear o sistema político e fazer valer direitos fundamentais ${ }^{33}$.

Uma outra lição valiosa que o caso proporciona é a de que decisões judiciais que afetam escolhas políticas de importante relevância não podem ser tratadas sem a

ocorreram durante aquela época e, acima de tudo, as questionaram. Temos sido forçados, como talvez devêssemos, a examinar a legitimidade de tais mudanças" (tradução nossa). FISS, Owen. The Forms of Justice. Harvard Law Review, v. 93, p. 1-58, 1979, p.21.

31 FISS, Owen. The Forms of Justice. Harvard Law Review, v. 93, p. 1-58, 1979, p.21.

32 FERRARO, Marcella Pereira. Do processo bipolar a um processo coletivo-estrutural. Dissertação de Mestrado. Curitiba: Universidade Federal do Paraná, 2015, p.120.

33 LIMA, Flavia Danielle Santiago; FRANÇA, Eduarda Peixoto da Cunha. Ativismo dialógico x bloqueios institucionais: limites e possibilidades do controle jurisdicional de políticas públicas a partir da Sentencia T025/04 da Corte Colombiana. Argumenta Journal Law, n. 31, p. 209-243, jul./dez., 2019, p.218. 
correspondente consciência do encargo assumido. Sentenças ou decisões interlocutórias que concedem vagas em sistemas públicos de saúde ou remédios custeados pelo Estado, vagas em creches ou escolas públicas, leitos em hospitais e manicômios, entre outros, não afetam somente as partes, num cenário episódico, mas todo o sistema. Essa atividade, portanto, deve ser realizada com prudência, visando a exequibilidade efetiva da operação institucional ${ }^{34}$.

Por isso, justifica-se que demandas desse cariz sejam tratadas, preferencialmente, no âmbito coletivo. Ações individuais dificilmente enfrentam a complexidade de problemas estruturais enraizados numa determinada localidade ou sequer atentam aos problemas enfrentados por grupos sociais menos favorecidos que precisam da derrocada de determinadas doutrinas, culturas ou práticas societárias - muitas vezes, perpetuadas há décadas - para ver os seus direitos efetivamente tutelados. Mas, para além da superação da dicotomia entre plano individual x coletivo, é necessária a adoção do modelo de processo estrutural.

\section{Modelos decisórios}

Não existe um procedimento único quando o assunto são os processos estruturais. Existem, em contrapartida, diversas experiências e diferentes tipos de abordagens em torno de um mesmo fim, qual seja: o de enfrentar desafios estruturais à efetivação de direitos por intermédio da formatação que melhor atende às peculiaridades locais. Como destaca Susan Sturm, a tutela jurisdicional nos litígios complexos é uma prática em busca de uma teoria ${ }^{35}$ e, assim sendo, traçar possíveis estratégias em modelos de decisão judicial pode se mostrar interessante. Não se olvida, no entanto, que a avaliação do sucesso das medidas adotadas, bem como do processo e o modus operandi do juiz, não é simples e não pode ser averiguada de maneira superficial. O risco do fracasso sempre existirá, pois existem diversos fatores

\footnotetext{
34“"A decisão judicial haverá de considerar as contingências e as necessidades do caso e das partes, adequando as imposições àquilo que seja concretamente viável. Decisões contra o Poder Público, por exemplo, exigirão a ponderação sobre a efetiva condição da Administração Pública em realizar o comando judicial, em que tempo e de que modo. Provimentos que imponham um fardo muito grande a réu particular, em geral, deverão atentar para as consequências do cumprimento, que podem levar à falência de uma empresa, à sua exclusão do mercado ou mesmo à indiabilidade concreta do atendimento à determinação judicial." ARENHART, Sérgio Cruz; OSNA, Gustavo. Curso de processo civil coletivo. São Paulo: Revista dos Tribunais, 2019, p.140.

${ }^{35}$ STURM, Susan. A Normative Theory of Public Law Remedies, Georgia Law Journal., v. 79, p.13551446,1990, p.1357-1358.
} 
capazes de influir na equação e a maior parte deles sequer é controlável pelo juiz ${ }^{36}$.

Ademais, antes de prosseguir, salienta-se que problemas estruturais de interesse público são um reflexo direto, também, do fracasso de outras instituições, de modo que não se torna cabível pensar somente em (in)sucesso do Judiciário ${ }^{37}$. Por mais que existam pesquisas em torno de qual o modelo de decisão judicial mais interessante para casos estruturais de interesse público, os estudos acerca da temática podem variar de acordo com, por exemplo, as expectativas do pesquisador e os critérios de efetividade adotados, além de terem uma conexão com o contexto político, social, cultural em que estão inseridas, bem como com a (in)disponibilidade das instituições públicas e privadas envolvidas de acolherem as medidas necessárias à mudança que se pretende ver efetivada.

Os exemplos apresentados no presente artigo, dessa forma, buscarão explorar as possíveis condutas que o magistrado pode adotar para formular, implementar e controlar medidas de reestruturação de instituições sociais violadoras, mas não pretende, em contrapartida, defender uma postura absoluta ou solução milagrosa para problemas complexos como os que serão expostos a seguir. A subdivisão se dará entre os modelos forte, deferente e compartilhado.

\subsection{Modelo "forte"}

O primeiro modelo de decisão judicial é aqui intitulado como "forte", no qual a figura do juiz é trazida para o centro do processo estrutural. As medidas estruturantes, por sua vez, são impostas pelo órgão jurisdicional, que age guiado por sua própria percepção das necessidades do caso em concreto ou com a ajuda de um expert nomeado pelo juízo ${ }^{38}$.

Se informações "extras" forem necessárias ao processo, o juiz tomará as medidas necessárias para investigá-las. Sua conduta, aqui, aproxima-se da de um administrador

\footnotetext{
${ }^{36}$ FERRARO, Marcella Pereira. Do processo bipolar a um processo coletivo-estrutural. Dissertação de Mestrado. Curitiba: Universidade Federal do Paraná, 2015, p.97.

37 Nesse sentido: " a intervenção judicial não deve ser avaliada no vácuo, mas em relação a outros esforços para realizar reformas institucionais." STURM, Susan. The legacy and future of corrections litigation. University of Pennsylvania Law Review, v.142, n.2, p.641-735, dez.1993, p.654.

${ }^{38}$ Também chamados de "special masters" VIOLIN, Jordão.Holt v. Sarver e a reforma do sistema prisional no Arkansas. In: ARENHART, Sérgio Cruz; JOBIM, Marco Félix (org.). Processos estruturais. Salvador: JusPodivm, p.303-353, 2017, p.329.
} 
judicial utilizando-se de uma postura ativista metodológica ${ }^{39}$, institucional ${ }^{40}$, e, muitas vezes, antidialógica $^{4142}$. Assemelha-se ao que Susan Sturm denomina de "juiz diretor"43.

As decisões estruturais da Suprema Corte Norte-Americana na década de 1964-1974 são bons exemplos desse modelo decisório ${ }^{44}$. No referido período, as medidas judiciais não se restringiam a definições genéricas, mas entravam em detalhes e especificidades, como, por exemplo: indicar a equipe de pessoal necessária em determinada instituição, a comida que deveria ser servida, quando e por quanto tempo um determinado detento poderia ficar na solitária, as cores das paredes e tamanhos dos sanitários nas celas, o currículo escolar dos professores nas instituições públicas de ensino e até mesmo o tratamento psiquiátrico que determinados pacientes deveriam receber ${ }^{4546}$.

\footnotetext{
${ }^{39}$ A dimensão metodológica (ou interpretativa) diz respeito ao modo de interpretar e aplicar os dispositivos constitucionais ou legais, expandindo ou reduzindo os "significados para além ou aquém dos sentidos mais imediatos e compreensíveis." CAMPOS, Carlos Alexandre de Azevedo. Dimensões do ativismo judicial do Supremo Tribunal Federal. Rio de Janeiro: Forense, 2014, p.166. O juiz, dessa forma, não se considera adstrito à aplicação passiva de normas preestabelecidas, mas participa ativa e criativamente da construção da ordem jurídica. A característica mais marcante dessa faceta de ativismo, portanto, seria uma espécie de criação judicial do direito pela expansão de uma norma constitucional aberta.

${ }^{40} \mathrm{~A}$ partir da perspectiva institucional, haveria ativismo quando os magistrados utilizam prerrogativas típicas dos ramos legislativo e executivo, como, por exemplo, a tomada de decisões políticas e a determinação de garantias para sua efetivação, no processo de interpretação da lei à luz da constituição. A característica principal dessa faceta, portanto, seria a que de os juízes, em determinados cenários, estariam "impondo suas preferências aos representantes eleitos e demais instâncias de poder, em detrimento das distribuições normativas de competências" e sua forma de aferição seria através de um método quantitativo. LIMA, Flávia Danielle Santiago Lima. Jurisdição constitucional e política: ativismo e autocontenção no STF. Curitiba: Juruá, 2014, p.189.

${ }^{41}$ Isso posto, entende-se que o ativismo antidialógico poderia ser comparado às hipóteses nas quais o Poder Judiciário emite decisões que não atentam para a necessidade de adesão dos demais poderes e outros atores constitucionais e sociais para que ela goze de efetividade. Em suma, situações nas quais a função jurisdicional é exercida de maneira solipsistas. Um maior aprofundamento na temática pode ser encontrado em CAMPOS, Carlos Alexandre de Azevedo. Dimensões do ativismo judicial do Supremo Tribunal Federal. Rio de Janeiro: Forense, 2014, p.170..

${ }^{42}$ As considerações acerca das dimensões do ativismo judicial que dizem respeito ao modelo decisório do presente tópico são impressões do presente estudo e não estão vinculados às ideias originais das obras referenciadas.

${ }^{43}$ STURM, Susan P. A normative theory of public law remedies. Georgia Law Review, v. 79, n.8, p. 13551446, 1990, p.1359.

${ }^{44}$ FERRARO, Marcella Pereira. Do processo bipolar a um processo coletivo-estrutural. Dissertação de Mestrado. Curitiba: Universidade Federal do Paraná, 2015, p.110.

${ }^{45}$ SABEL, Charles F.; SIMON, William H. Destabilization rights: How public law litigation succeeds. Harvard Law Review, v. 117, p. 1016-1101, fev. 2004, p.1031.

${ }^{46}$ Esse modelo decisório também equipara-se ao caso Wyatt v. Stickney, que envolvia às condições a que estavam sujeitas as pessoas internadas para tratamento psiquiátrico no Bryce Hospital, no Alabama. A decisão judicial determinava, por exemplo, que houvesse um banheiro para cada oito pacientes e seis destes por quarto, bem como qual seria o espaço que cada um teria nos dormitórios e no refeitório e qual deveria ser a temperatura do ar e da água. SABEL, Charles F.; SIMON, William H. Destabilization rights: How public law litigation
} 
Exemplica-se este modelo decisório com o caso da reforma prisional em Pugh $v$. Locke, no qual, após uma longa instrução, o juiz proferiu uma decisão determinando detalhadamente quais seriam as medidas a serem tomadas no dia a dia do estabelecimento prisional. A ordem, dessa forma, foi desenvolvida unilateralmente pela Corte norteamericana, sem que houvesse um engajamento significativo das partes em seu detalhamento e baseou-se nas evidências encontradas na fase probatória ${ }^{47}$.

Nesse seguimento, aponta-se três características basilares do modelo forte: 1) a rigidez da decisão judicial; 2) a especificação detalhada dos meios a serem utilizados para alcançar os objetivos visados; 3) um forte papel diretivo do juiz na condução do procedimento, que dificulta um modelo cooperativo e participativo por deixar uma baixa margem de possibilidades para que as instituições públicas e/ou privadas, bem como indivíduos interessados, exerçam um papel significativo na construção dos meios que serão utilizados para chegar à transformação almejada.

Os pontos positivos de decisões que adotam esse modelo são: i) simplificações procedimentais, com considerável redução da complexidade do processo; ii) superação de eventuais indisposições dos envolvidos para o desenvolvimento da solução; iii) o estabelecimento especificado de planos de ação que facilitem o controle de seu cumprimento e atingimento das metas judicialmente estabelecidas; iiii) a sobrelevação do compromisso do juiz para com a proteção do valor público subjacente à decisão ${ }^{48}$.

Os aspectos negativos, em contrapartida, são: a) falta de capacidade institucional do Poder Judiciário para decidir de forma adequada questões de alta complexidade técnica (à medida que se sobreleve esse fator, menos viável será a formulação unilateral do plano, tornando a decisão impraticável); b) considerável redução da participação dos envolvidos no litígio (o que tende a destacar as objeções acerca da falta de legitimidade democrática do Poder Judiciário e dificultar a aderência sociopolítica à decisão estruturante); c) A cumulação de funções na figura do juiz - funções de desenvolver e, ao mesmo tempo, avaliar a adequação do plano de reestruturação - , que pode trazer riscos à imparcialidade do órgão

\footnotetext{
succeeds.Harvard Law Review., v. 117, p. 1016-1101, fev. 2004, p.1031.

${ }^{47}$ STURM, Susan P. A normative theory of public law remedies. Georgia Law Review, v. 79, n.8, p. 13551446, 1990, p.1357.

${ }^{48}$ PICOLI, Bruno de Lima. Processo estrutural. Dissertação de Mestrado. Curitiba: Universidade Federal do Paraná, 2018, p.91.
} 
julgador quando do exame dos resultados práticos da decisão por si estruturada ${ }^{49}$.

\subsection{Modelo Deferente}

O modelo deferente traz às partes e aos outros atores constitucionais o protagonismo na implementação da reforma. Essa conduta pode ocorrer através da delegação da formulação do plano de reestruturação à própria instituição e grupos afetados e a partir da deferência para com as escolhas administrativas e legislativas. Foi a estratégia utilizada no famoso caso de Holt v. Sarver, oportunidade na qual procurou-se desenvolver a cessação da violação massiva a direitos fundamentais no sistema prisional do Estado do Arkansas. Holt foi uma class action ajuizada por detentos do complexo prisional Cummins em face do chefe da Comissão de Correções Robert Sarver, cujo intuito central era colocar em xeque o caráter cruel e incomum do confinamento em solitária, a negativa de tratamento médico e dentário aos internos e, por fim, a falta de condições do Estado em proteger a vida e a integridade física dos detentos, em violação a seus direitos ${ }^{50}$ fundamentais.

Apesar de ter reconhecido o dever do Estado de proteger a vida e a integridade dos detentos, bem como a existência de uma situação fática degradante no sistema prisional, a sentença restringiu-se a estabelecer "sugestões" de caráter genérico aos agentes responsáveis. Isso ocorreu pelo fato dos magistrados confiarem no esforço da administração pública para reorganizar o sistema, bem como na autonomia do Poder Executivo para conformar seu sistema prisional e ponderar escolhas diante da escassez orçamentária existente ${ }^{51}$.

Na sentença, argumentou-se que a Corte não se utilizaria daquela oportunidade para prescrever quaisquer passos específicos e imediatos a serem tomados pelo requerido, pois

\footnotetext{
${ }^{49}$ STURM, Susan P. A normative theory of public law remedies. Georgia Law Review, v. 79, n.8, p. 13551446, 1990, p.1413.

${ }^{50}$ VIOLIN, Jordão.Holt v. Sarver e a reforma do sistema prisional no Arkansas. In: ARENHART, Sérgio Cruz; JOBIM, Marco Félix (org.). Processos estruturais. Salvador: JusPodivm, p.303-353, 2017, p.305.

${ }^{51}$ Além disso, houve uma ampla adesão da causa pela opinião pública, que colocou-se a favor da causa e trouxe, consequentemente, o apoio - mesmo que vacilante - do Executivo e do Legislativo. Assim, apesar de não se poder falar em um "clamor público", pode-se entender que a população tolerou a maior destinação de recursos aos presídios. VIOLIN, Jordão.Holt v. Sarver e a reforma do sistema prisional no Arkansas. In: ARENHART, Sérgio Cruz; JOBIM, Marco Félix (org.). Processos estruturais. Salvador: JusPodivm, p.303353,2017, p.336.
} 
desejava, primeiramente, saber o que este pensava que poderia fazer e o que ele poderia se comprometer a fazer ${ }^{52}$. A adoção de acordos com o intuito de viabilizar a reforma institucional é uma estratégia amplamente utilizada no contexto do país ${ }^{53}$.

Os pontos positivos são: i) mitigar as objeções à falta de expertise do Judiciário no controle de políticas públicas (afinal, a delegação do plano de reestruturação às partes ou às instituições violadoras reduz o grau de interferência jurisdicional sobre a atividade legislativa e executiva, remetendo-se aos órgãos com maior legitimidade e capacidade a tarefa de remodular sua conduta); ii) garante-se uma maior imparcialidade do juiz.

Os obstáculos, todavia, são os seguintes: a) conseguir fazer com que haja cooperação das partes, visto que nem sempre a instituição violadora estará comprometida com a cessação da violação massiva a direitos fundamentais e tampouco existe garantia de que os grupos afetados estarão interessados na autocomposição ${ }^{54}$. Nas hipóteses em que delega-se o plano ao agente violador, usualmente, são utilizados métodos indutivos de colaboração (como, por exemplo, a designação de multa cominatória). No que concerne à tentativa de estabelecimento de acordos entre as partes, é possível a utilização de audiências de conciliação ou a submissão do litígio a órgãos de conciliação e mediação ${ }^{5566}$-. Ainda assim, em nenhuma dessas opções, existe garantia de cooperação dos interessados.

O segundo obstáculo, por sua vez, é: b) uma atuação deferente tende a limitar a capacidade do juiz em averiguar a justiça das medidas propostas bem como sua congruência com as dificuldades que o caso revela, o que reduz a aptidão do órgão jurisdicional em cooperar para que bons resultados sejam assegurados.

\subsection{Modelo compartilhado}

\footnotetext{
${ }^{52}$ PICOLI, Bruno de Lima. Processo estrutural. Dissertação de Mestrado. Curitiba: Universidade Federal do Paraná, 2018, p.86.

${ }^{53}$ ROQUE, André Vasconcelos. Class Actions- Ações Coletivas nos Estados Unidos: O que podemos aprender com eles?. Salvador: JusPodivm, 2013. p. 346-350.

${ }^{54}$ PICOLI, Bruno de Lima. Processo estrutural. Dissertação de Mestrado. Curitiba: Universidade Federal do Paraná, 2018, p.94.

${ }^{55}$ A utilização dessas ferramentas, todavia, não exclui a possibilidade de que os interesses de determinados grupos sejam ignorados.

${ }^{56}$ STURM, Susan P. A normative theory of public law remedies. Georgia Law Review, v. 79, n.8, p. 13551446, 1990, p.1415.
} 
O processo decisório no qual o juiz está comprometido em fazer concessões e, ao mesmo tempo, assumir responsabilidades num modelo "dialógico", intitula-se, no presente estudo, de "modelo compartilhado". Nessa hipótese, busca-se fomentar a interação de forma ampliada entre a instituição (ou instituições) violadora (s) e a sociedade impactada, bem como aos órgãos administrativos e/ou legislativos. O modelo compartilhado assemelha-se ao experimentalismo defendido por Sabel e Simon. Os autores propõem que, em casos estruturais, os direitos invocados funcionam como "direitos desestabilizadores", que articulam uma espécie de "incômodo" na instituição que não está satisfazendo os padrões mínimos de desempenho. O processo, assim, desestabiliza as expectativas iniciais das partes por intermédio de efeitos de diferentes naturezas (políticas, cognitivas, psicológicas, por exemplo) e abre espaço para uma "colaboração experimentalista"

As características centrais desse modelo seriam: a ampla participação dos interessados e a possibilidade de negociação entre eles (pois o processo não é fechado nem hierarquizado); o estabelecimento de objetivos gerais por parte do órgão judicial - ao invés de ordens detalhadas-, permitindo que o enfoque do processo seja mais na solução do problema que na indicação de medidas que disponham como os objetivos visados serão atingidos; a flexibilidade (que viabiliza o ciclo de tentativa-acerto/erro-ajuste) e revisão contínua (que é mais efetiva para a garantia de que as medidas estão sendo cumpridas que a imposição pura e simples de ordens fortes, pois os procedimentos vão sendo alterados conforme os problemas vão surgindo; transparência (visando garantir que as normas, ainda que genéricas e provisórias, sejam explícitas e públicas ${ }^{58}$.

Uma estratégia semelhante, nesse sentido, foi empregada a no caso estrutural argentino "Mendoza, Beatriz y ots. c/ Estando Nacional y ots." ${ }^{59}$. Mendoza versava sobre um problema ambiental e social profundo do país, que teve suas raízes no início do século XIX: a poluição da bacia ambiental Matanza-Riachuelo, cuja superfície total é de aproximadamente $2.250 \mathrm{~km} 2$, região na qual habitam mais de cinco milhões de pessoas,

57 SABEL, Charles F.; SIMON, William H. Destabilization rights: How public law litigation succeeds.Harvard Law Review., v. 117, p. 1016-1101, fev. 2004, p.1062.

58 SABEL, Charles F.; SIMON, William H. Destabilization rights: How public law litigation succeeds.Harvard Law Review., v. 117, p. 1016-1101, fev. 2004 p.1063.

${ }^{59}$ BERGALLO, Paola. La causa "Mendoza": una experiencia de judicialización cooperativa sobre el derecho a la salud. In: GARGARELLA, Roberto (org.) Por una justicia dialógica: el Poder Judicial como promotor de la deliberación democrática. Buenos Aires: Siglo XXI, p. 245-291, 2014, p.246. 
aproximadamente $13 \%$ de toda a população do país. A bacia é conhecida por ser extremamente poluída, já que desde 1871 era descrita como "rio sem cor nem odor de água".

A ação foi ajuizada na "Corte Suprema de Justicia de la Nación (CSJN) por um grupo de pessoas que vivia na zona de poluição contra o Estado Nacional, a Província de Buenos Aires, a Cidade Autônoma de Buenos Aires e quarenta e quatro empresas locais. Os objetivos centrais eram: 1) reparar danos ambientais; 2) criar um fundo público para reparação de danos individuais homogêneos; 3) impor ao Poder Executivo que reativasse e continuasse a execução do plano de gestão ambiental; 5) implementar medidas urgentes para atender a saúde da população ${ }^{60}$.

Na primeira decisão (que ocorreu em vinte de junho de dois mil e seis), a Corte restringiu sua competência às matérias que dissessem respeito a danos de incidência coletiva, afastando quaisquer pretensões de reparações individuais. Ainda, argumentou que a formulação inicial não dispunha de informações o suficiente para embasar o pedido dos autores, mas que isso não desencadearia o indeferimento do pleito. Ao contrário, a Corte assumiu papel ativo na instrução e ordenação do feito, determinando que: a) as empresas demandadas prestassem informações sobre aspectos relacionados ao caso; b) que o Estado Nacional, Província, Cidade Autônoma e Conselho Federal do Meio Ambiente apresentassem plano integrado contemplando atividades voltadas à resolução do conflito; c) a convocação de audiência pública com o intuito de que as partes informassem à Corte sobre o plano integrado; d) os demandantes aprimorassem sua petitória por meio do aporte das informações faltantes, com o escopo de viabilizar o adequado procedimento do feito ${ }^{61}$.

Após uma longa instrução, a Corte proferiu uma sentença determinando a tomada de múltiplas medidas para recompor o meio-ambiente e evitar a continuidade dos danos, ressaltando, ademais, que sua decisão tinha caráter prospectivo ${ }^{62} \mathrm{e}$, consequentemente,

60 VERBIC, Francisco. El remedio estructural de la causa "Mendoza": Antecedentes, principales características y algunas cuestiones planteadas durante los primeros tres años de su implementación. Anais Facultad de Ciencias Jurídicas y Sociales (U.N.L.P), v. 43, p. 267-286, 2013. Disponível em: <http://sedici.unlp.edu.ar/bitstream/handle/10915/33771/Documento_completo.pdf?sequ ence=1>. Acesso em: 20 abr. 2020, p.272.

61 VERBIC, Francisco. El remedio estructural de la causa "Mendoza": Antecedentes, principales características y algunas cuestiones planteadas durante los primeros tres años de su implementación. Anais Facultad de Ciencias Jurídicas y Sociales (U.N.L.P), v. 43, p. 267-286, 2013. Disponível em: $<$ http://sedici.unlp.edu.ar/bitstream/handle/10915/33771/Documento_completo.pdf?sequ ence=1>. Acesso em: 20 abr. 2020 , p.272.

62 Sobre o caráter prospectivo do processo estrutural: “(...)a diferença do modelo processual decorre de uma 
delimitava-se a fixar critérios gerais para cumprir com a tutela buscada. Para além das medidas específicas e da reparação do dano ambiental, determinou a criação de meios de comunicação e informações sociais a fim de que a população pudesse controlar o cumprimento das medidas e auxiliar no desenvolvimento do plano.

Após serem estabelecidas as diretrizes gerais pela Corte, esta delegou o cumprimento da decisão ao Juízo Federal de Primeira Instância de Quilmes, autorizando a tomada de medidas necessárias a fim de garantir a concretização do programa ${ }^{63}$. A delegação ocorreu, sobretudo, da necessidade de controlar a agenda da Corte Suprema e, também, em decorrência da busca de uma relação mais próxima entre magistrados e as partes envolvidas. O juiz de primeira instância, ademais, ficou encarregado de controlar as decisões da ACUMAR (entidade da administração pública especialmente criada para viabilizar a despoluição da região) ${ }^{64}$.

Embora não tenha sido completamente solucionado, o dano ambiental foi consideravelmente reduzido $^{65}$. O modelo compartilhado dá enfoque num diálogo com a sociedade afetada e com as instituições (públicas ${ }^{66}$ e/ou privadas) violadoras, buscando elaborar decisões embasadas ao máximo em consensos e construções sociais, potencializando medidas colaborativas. Objeções acerca da falta de legitimidade democrática e capacidade institucional do Judiciário são mitigadas, pois seu modo de operacionalização engaja os participantes das instituições contra quem as medidas

mudança de racionalidade, de uma relação causa-efeito (retrospectiva) para uma relação meio-fim (prospectiva) entre fatos e efeitos." GALDINO, Matheus. Processos Estruturais: uma transição entre estados de coisa para a tutela dos direitos.Revista Eletrônica de Direito Processual, v. 20, n. 3, p.358-384, 2019, p.361.

${ }^{63}$ PICOLI, Bruno de Lima. Processo estrutural. Dissertação de Mestrado. Curitiba: Universidade Federal do Paraná, 2018, p.94.

${ }^{64}$ VERBIC, Francisco. El remedio estructural de la causa "Mendoza": Antecedentes, principales características y algunas cuestiones planteadas durante los primeros tres años de su implementación. Anais - Facultad de Ciencias Jurídicas y Sociales (U.N.L.P), v. 43, p. 267-286, 2013. Disponível em: $<$ http://sedici.unlp.edu.ar/bitstream/handle/10915/33771/Documento_completo.pdf?sequ ence=1>. Acesso em: 20 abr. 2020, p.278.

${ }^{65}$ PICOLI, Bruno de Lima. Processo estrutural. Dissertação de Mestrado. Curitiba: Universidade Federal do Paraná, 2018, p.98.

66 "As decisões estruturais devem levar em conta todos os fatores envolvidos no caso, de modo a produzir um resultado fático viável, considerando as condições dos atores envolvidos de efetivamente concretizarem os comandos emanados do provimento. Especialmente quando envolvem os entes públicos, devem procurar harmonizar a solução buscada com as possibilidades reais de a administração pública realizá-la, a fim de que não se torne um estorvo." CASTELO, Fernando Alcântara. Direito à Saúde e Decisões Estruturais: Por uma judicialização mais racional e eficiente. Revista de Processo, v.274, p.1-18, dez. 2017, p.6. 
reformatórias serão impostas e insere a sociedade civil no processo, colocando-a enquanto agente influente na construção do feito, o que auxilia no cumprimento e eficácia das medidas. $\mathrm{O}$ fato de uma ampla gama de agentes estarem envolvidos viabiliza um ambiente no qual a Corte tem, efetivamente, mais acesso a informações que, verdadeiramente, são pertinentes à superação da situação violadora de direitos.

Esse tipo de abordagem, dessa forma, é interessante pois não ignora as dificuldades, complexidades e variantes do trâmite do processo estrutural de interesse público, permitindo, ainda, um aprimoramento da capacidade institucional do Judiciário sem, contudo, atribuí-lo um papel hercúleo - sobretudo porque nenhuma instituição, pública ou privada, tem habilidade o suficiente para enfrentar problemas desse cariz sozinha ${ }^{6}{ }^{67}$.

Os aspectos negativos, em contrapartida, são os seguintes: 1) esse modelo decisório demanda a utilização de mais recursos públicos quando comparado aos modelos anteriores, uma vez que quanto mais agentes envolvidos - tanto para a formulação quanto o controle das medidas - , mais dinheiro precisará ser disponibilizado; 2) o modelo depende, necessariamente, da disponibilidade do juiz em acompanhar o feito, o que nem sempre será viável, uma vez que muitas são as demandas que chegam diariamente ao Judiciário brasileiro $^{68}$; 3) um processo dialógico na tomada de decisão judicial prescinde de mais tempo, a fim de que seja garantido a manifestação e participação do máximo de atores envolvidos.

\section{Conclusão}

Problema estruturais que, ao mesmo tempo, são de interesse público, não são alheios ao Judiciário e, frequentemente, chegam ao mesmo através de demandas individuais, desafiando políticas públicas existentes ou defendendo a necessidade de sua criação. Ainda que constatada a disposição dos magistrados em adotar uma postura proativa no processo, o modo individualístico como essa proteção vem sendo efetivada não tem dado resposta à fonte dos problemas, mas, tão somente, figurado como medidas paliativas. Esse tratamento

67 FERRARO, Marcella Pereira. Do processo bipolar a um processo coletivo-estrutural. Dissertação de Mestrado. Curitiba: Universidade Federal do Paraná, 2015, p.118.

68 LIMA, Edilson Vitorelli Diniz. O devido processo legal coletivo: representação, participação e efetividade da tutela jurisdicional. Tese de Doutorado. Curitiba: Universidade Federal do Paraná, 2015, p.525-526. 
individual pode dar margem: a) a uma atuação antidialógica por parte do magistrado; b) à violação da isonomia, uma vez que cada magistrado, muito provavelmente, decidirá de forma diferente acerca de uma mesma questão; c) a privilégios, já que somente aqueles que têm acesso à justiça serão beneficiados (e esses não são, necessariamente, aqueles que mais precisam); 4) a prejuízos nas políticas públicas eventualmente existentes.

Nesse sentido, destacou-se que uma das principais características dos ditos "litígios estruturais de interesse público" é a acentuada intervenção judicial no monitoramento e regulação dos sujeitos envolvidos no processo - sejam eles particulares ou públicos ${ }^{69}$ - o que desperta, recorrentemente, os já muito trabalhados questionamentos acerca dos limites e possibilidades do judicial review. Em contrapartida, apontou-se o modelo decisório "compartilhado" enquanto possível solução normativa para a superação parcial tanto da suposta falta de legitimidade democrática quanto da falta de expertise do Judiciário, uma vez que permitiria a participação de atores sociais, políticos e constitucionais envolvidos direta ou indiretamente na litis, tornando o procedimento de superação das falhas estruturais um espaço colaborativo e plural.

As ações estruturais não se limitam a ser um movimento jurisdicional, pois envolvem, imprescindivelmente, práticas políticas ${ }^{70}$. Apesar das cortes, muitas vezes, funcionarem enquanto canal inicial de debate nesses casos, o fato de continuarem ou não a serem arenas de discussão no processo, bem como os fracassos ou sucessos advindos da sentença não se limitam somente à sua atuação, pois envolvem objetivos, recursos, disponibilidade e ações de muitos grupos e atores, que são igualmente responsáveis pelo progresso ou regresso na superação do estado de coisas violador de direitos. Dessa forma, é importante que, ao analisar esses casos, pesquisadores, juristas, cientistas políticos e demais interessados, necessariamente, atentem não apenas ao papel que o juiz deve desempenhar, mas também ao papel que todos os envolvidos - direta ou indiretamente no caso sub judice - precisam assumir, bem como ao conjunto de fatores históricos, políticos e sociais que afligem o cenário no qual a decisão se insere ${ }^{71}$.

${ }^{69}$ DIDIER JR, Fredie; ZANETI JR, Hermes; OLIVEIRA, Rafael Alexandria de. Notas sobre as decisões estruturantes. Civil Procedure Review, v. 8, n. 1, p. 46-64, 2017, p.48.

70 SCHLANGER, Margo. Beyond the hero judge: institutional reform litigation as litigation. Michigan Law Review, v. 97, n.6, p.1-44, 1999, p.30.

${ }^{71}$ Importante ressaltar, ainda nesse sentido, que as diversas perspectivas daquilo que se entende como sucesso das decisões estruturais depende diretamente da perspectiva e das expectativas que o observador estabelece 
Ademais, entende-se que um dos pontos chaves na apreciação dos referidos casos é a prolação de decisões consequencialistas, com escopos palpáveis e condizentes com a realidade $^{72}$. Nesse sentido, o diálogo - próprio do modelo compartilhado - contribui para com uma percepção mais objetiva das cortes em relação ao problema, uma vez que a contribuição dos atores envolvidos direta ou indiretamente no conflito trazem à pauta decisória aspectos que não poderiam ser deduzidos, imaginados ou aferidos de ofício pelo juízes, posto que existe um limite intransponível entre a experiência daqueles que vivenciam o problema (realidade fática) e a capacidade de aproximação de um observador externo, por mais engajado que este esteja na causa.

Ainda que o magistrado se esforce, existem questões técnicas, financeiras e até mesmo burocráticas que ele não domina e que precisam ser consideradas quando da definição de "como" e "quando" determinados quesitos precisam ser tratados ${ }^{73}$. Assim, se a decisão judicial for subsidiada por elementos que o juiz, solitariamente, não teria acesso e sem os quais, muito provavelmente, adotaria medidas que não gozariam de eficácia prática, possui mais chances de causar impactos positivos na superação da questão.

Litígios estruturais de interesse público enfrentam problemas demasiadamente complexos - que não se restringem à procedência/improcedência do pedido, mas adentram em campos como a escassez de recursos, a discricionariedade alocativa de orçamento público, a inexistência de programas estabelecidos em lei, dificuldades de implementação de políticas públicas, etc - de forma que não podem ser tratados sem que haja uma observância das consequências e impactos dos remédios utilizados na realidade local.

Além disso, lidam, não raramente, com problemáticas sociais arraigadas, cuja solução não é alcançada por meio de medidas simples, mas sim através da mudança de paradigmas da sociedade como um todo ou da adoção de mecanismos que levam mais de

enquanto padrão de êxito. STURM, Susan. The legacy and future of corrections litigation. University of Pennsylvania Law Review, v.142, n.2, p.641-735, dez.1993, p.654.

72 “Uma vez que as decisões estruturantes podem provocar mudanças institucionais de grande importância, é fundamental que o julgador leve em consideração os mais diversos fatores envolvidos, inclusive as consequências sociais, políticas e econômicas que podem advir da decisão. Para tanto, torna-se fundamental a valorização do contraditório, o amplo diálogo e a cooperação entre os envolvidos para que se possa ter uma decisão realmente exequível." CASTELO, Fernando Alcântara. Direito à Saúde e Decisões Estruturais: Por uma judicialização mais racional e eficiente. Revista de Processo, v.274,p.1-18, dez. 2017, p.6.

73 THEODORO JUNIOR, Humberto; NUNES, Dierle José Coelho; BAHIA, Alexandre Melo Franco. Litigância de interesse público e execução comparticipada de políticas públicas. Revista de Processo, v.4, n,23, p. 121-152, jun. 2013, p.146. 
uma geração para surtir efeitos. Dessa forma, independentemente das intenções do julgador que exarou a medida tendente a afastar violação constitucional, resultados empíricos dependem, também, em algumas circunstâncias, de uma mudança de mentalidade e conscientização da população sobre o respeito, na prática, dos direitos constitucionais.

A compreensão da formatação dos litígios estruturais de interesse público - bem como do modelo decisório que melhor os contempla na perspectiva normativa - é importante para o reforço da premissa de que transformações sociais só são viáveis através de esforços compartilhados entre uma ampla gama de atores, sem os quais a decisão judicial, muito provavelmente, teria um cunho meramente declaratório. Entretanto, a partindo de uma perspectiva pragmática, é relevante ressaltar que, conforme as circunstâncias fáticas é que as estratégias de atuação judicial devem ser estabelecidas. Isso porque, tendo em vista o amplo leque de possibilidades na correção das violações de direitos, mais importante que defender uma forma específica de decisão judicial, é utilizá-las estrategicamente de maneira contingente, a depender do caso concreto.

Kent Roach e Geoff Budlender, nesse sentido, apresentam ser possível que uma determinada decisão judicial esteja inserida em cenários divergentes, tais quais aqueles em que: a) sabe-se, de antemão, que não haverá cumprimento da ordem judicial ou que não seria adequado o tribunal supor que haveria cumprimento de pronto - por existirem situações anteriores que corroborem isso -; b) as consequências do descumprimento podem ser demasiadamente danosas - e até mesmo irreparáveis -, ainda que o responsável pela adoção das medidas em concreto esteja de boa fé, de forma que o tribunal, com antecedência, busca garantir o seu cumprimento através da supervisão - ou seja, os juízes não esperam o descumprimento da decisão para depois tomar as medidas que busquem efetivá-la; e c) não é possível saber o que deve ser hipótese, hipótese na qual são designadas ordens abertas genéricas, ficando o encargo de apresentar um plano ao tribunal nas mãos do órgão responsável (que devem, também, dar publicidade ao que será implementado) ${ }^{74}$.

\footnotetext{
74 Nesse sentido, Gerald Rosenberg acredita que os processos estruturais, em geral, são ineficazes, pois o Judiciário tem uma capacidade limitada para promover mudanças sociais. Falta-lhe poder para implementar a sua própria decisão. Assim, para o autor, os casos estruturais só lograriam êxito quando tivessem o apoio do Executivo, do Legislativo e da opinião pública (ou, pelo menos, baixa oposição da opinião pública), de forma que a mudança social não estaria vinculada diretamente à determinação judicial, mas sim, à disposição dos outros poderes em efetivá-la ou não. ROSENBERG, Gerald N.The hollow hope: Can courts bring about social change?. Chicago: University of Chicago Press, 1991, p.53-56. A crítica de Rosenberg é rebatida por Susan Sturm, que argumenta que Rosenberg ignora a interdependência existente entre Judiciário, Executivo e
} 
Dessa maneira, observa-se as reais capacidades existentes para resolver a situação violadora de direitos constitucionais ou, se inexistentes, formula-se uma saída para gerá-las, podendo-se, a partir da perspectiva pragmática, utilizar os modelos forte, fraco ou deferente de acordo com o caso em questão.

\section{REFERÊNCIAS}

ARENHART, Sérgio Cruz; OSNA, Gustavo. Curso de processo civil coletivo. São Paulo: Revista dos Tribunais, 2019.

ARENHART, Sérgio Cruz. A tutela coletiva de interesses individuais: para além da proteção dos interesses individuais homogêneos. 2. ed. São Paulo: Revista dos Tribunais, 2014.

ARENHART, Sérgio Cruz. Decisões estruturais no direito processual civil brasileiro. Revista de Processo, v.38, n. 225, p. 389-410, dez. 2013.

ARENHART, Sérgio Cruz. Processos estruturais no direito brasileiro: reflexões a partir do caso da ACP do carvão. Revista de Processo Comparado, v.1, p.211-229, jul./dez, 2015.

ARENHART, Sérgio Cruz. Processo multipolar, participação e representação de interesses concorrentes. In: ARENHART, Sérgio Cruz; JOBIM, Marco Félix (org.). Processos estruturais. Salvador: JusPodivm, 2017, p.423-448.

BERGALLO, Paola. La causa "Mendoza": una experiencia de judicialización cooperativa sobre el derecho a la salud. In: GARGARELLA, Roberto (org.) Por una justicia

\footnotetext{
Legislativo. Afinal, ao alegar que as transformações sociais só ocorreram por causa da aderência dos poderes eleitos pelo princípio majoritário, o autor não leva em consideração o papel que o Judiciário desempenha em exortá-los. STURM, Susan. The legacy and future of corrections litigation. University of Pennsylvania Law Review, v.142, n.2, p.641-735, dez.1993, p.656-657. Ainda nesse sentido, em outra a oportunidade, a autora salienta que, no caso Holt v Sarver, o Legislativo apresentou uma considerável resistência em destinar recursos à reforma prisional, uma vez que muitos parlamentares não queriam vincular-se à ideia de proteção de direitos de criminosos. Afinal, a postura abstencionista não interferiria no rendimento dos mesmos nas urnas, uma vez que os presidiários não teriam direitos políticos e que parte da população apoiava esse tipo de conduta. STURM, Susan. Resolving the remedial dilemma: Strategies of judicial intervention in prisons. University of Pennsylvania Law Review, v.138, n.3, p.807-910. jan.1990, p.840. Destaca-se, ainda na mesma obra, a nota de rodapé n.148, na qual a autora transcreve trechos de argumentos que foram utilizados em entrevistas nas quais alguns parlamentares criticam o Comissário de Correções do Mississipi por ser "frouxo com o crime" (soft on crime) e destacando que a população gostaria de uma resposta firme por parte do legislativo ("people at home want us to get tough").
} 
dialógica: el Poder Judicial como promotor de la deliberación democrática. Buenos Aires: Siglo XXI, p. 245-291, 2014.

BARROSO, Luís Roberto. Constituição, democracia e supremacia judicial: direito e política no Brasil contemporâneo. Revista jurídica da presidência, v. 12, n. 96, p. 05-43, 2010 .

CAMPOS, Carlos Alexandre de Azevedo. Dimensões do ativismo judicial do Supremo Tribunal Federal.Rio de Janeiro: Forense, 2014.

CASTELO, Fernando Alcântara. Direito à Saúde e Decisões Estruturais: Por uma judicialização mais racional e eficiente. Revista de Processo, v.274, p.1-18, dez. 2017.

CHAYES, Abram. The Role of the Judge in Public Law Litigation. Harvard Law Review, v. 89, n. 7 , p. 1.281-1.316, mai. 1976.

DALLA, Humberto; CÔRTES, Victor Augusto Passos Villani. As medidas estruturantes e a efetividade das decisões judiciais no ordenamento jurídico brasileiro.Revista Eletrônica de Direito Processual, v. 13, n. 13,p.229-258, 2014

DIAS, Jean Carlos. O controle judicial de políticas públicas. Salvador: Juspodium, 2016.

DIDIER JR, Fredie; ZANETI JR, Hermes; DE OLIVEIRA, Rafael Alexandria. Elementos para uma teoria do processo estrutural aplicada ao processo civil brasileiro. Revista de Processo, v. 303, n. 2020, p. 45-81, 2020.

DIDIER JR, Fredie; ZANETI JR, Hermes; OLIVEIRA, Rafael Alexandria de. Notas sobre as decisões estruturantes. Civil Procedure Review, v. 8, n. 1, p. 46-64, 2017.

FERRARO, Marcella Pereira. Do processo bipolar a um processo coletivo-estrutural. Dissertação de Mestrado. Curitiba: Universidade Federal do Paraná, 2015.

FISS, Owen.The law as it could be. New York: New York University Press, 2003.

FISS, Owen. The Forms of Justice. Harvard Law Review, v. 93, p. 1-58, 1979.

FULLER, Lon. The forms and limits of adjudication. Harvard Law Review, v. 92, n. 2, p. 353-409, 1978.

GALDINO, Matheus. Processos Estruturais: uma transição entre estados de coisa para a tutela dos direitos.Revista Eletrônica de Direito Processual, v. 20, n. 3, p.358-384, 2019.

GAURI, Varun; BRINKS Daniel. A new policy landscape: legalizing social and economic rights in the Developing World. In: GAURI, Varun; BRINKS, Daniel (Org). Courting 
social justice: judicial enforcement of social and economic rights in the developing world. New York: Cambridge University Press, 2000, v.1, cap.6, p.303-354.

JOBIM, Marcos Félix; ROCHA, Marcelo Hugo. Medidas estruturantes: origem em Brown v. Board of Education. In: ARENHART, Sérgio Cruz; JOBIM, Marco Félix (org.). Processos estruturais. Salvador: JusPodivm, p.563-582, 2017.

LIMA, Edilson Vitorelli Diniz. O devido processo legal coletivo: representação, participação e efetividade da tutela jurisdicional. Tese de Doutorado. Curitiba: Universidade Federal do Paraná, 2015.

LIMA, Edilson Vitorelli Diniz. Levando os conceitos a sério: processo estrutural, processo coletivo,processo estratégico e suas diferenças. Revista de Processo, v. 284, n. 28, p. 333-369, jan. 2018.

LIMA, Flavia Danielle Santiago; FRANÇA, Eduarda Peixoto da Cunha. Ativismo dialógico $\mathrm{x}$ bloqueios institucionais: limites e possibilidades do controle jurisdicional de políticas públicas a partir da Sentencia T-025/04 da Corte Colombiana. Argumenta Journal Law, n. 31, p. 209-243, jul./dez., 2019.

LIMA, Flávia Danielle Santiago Lima. Jurisdição constitucional e política: ativismo e autocontenção no STF. Curitiba: Juruá, 2014.

MACHADO, Maíra Rocha. O estudo de caso na pesquisa em direito. In: MACHADO, Maíra (org). Pesquisar empiricamente o direito. São Paulo: Rede de Estudos Empíricos em Direito, p. 356-390, 2017.

MAGALHÃES, Breno Baía. A incrível doutrina de um caso só: análise do estado de coisas inconstitucional na ADPF 347. Revista Eletrônica do Curso de Direito da UFSM, Santa Maria, RS, v. 14, n. 3, e32760, set./dez. 2019.

MANCUSO, Rodolfo de Camargo. A resolução dos conflitos e a função judicial no contemporâneo Estado de Direito. São Paulo: Revista dos Tribunais, 2009

MITIDIERO, Daniel. O processualismo e a formação do Código Buzaid. Revista de Processo. Vol. 183, p. 165-194, maio.2010.

NUNES, Leonardo Silva; COTA, Samuel Paiva; FARIA, Ana Maria Damasceno de Carvalho. Dos litígios aos processos estruturais: pressupostos e fundamentos. In: Juliana Cordeiro de Faria Ester Camila Gomes Norato Rezende Edgard Audomar Marx Neto (org.). Novas tendências, diálogos entre direito material e processo. 
Belo Horizonte: Editora D’Plácido, 2018 p.365-383.

PICOLI, Bruno de Lima. Processo estrutural. Dissertação de Mestrado. Curitiba: Universidade Federal do Paraná, 2018.

ROACH, Kent; BUDLENDER, Geoff. Mandatory Relief and Supervisory Jurisdiction: When is it Appropriate, Just and Equitable?.South African Law Journal, v. 122, p. 325-351, 2005.

ROSENBERG, Gerald N. The hollow hope: Can courts bring about social change? Chicago: University of Chicago Press, 1991.

ROQUE, André Vasconcelos. Class Actions- Ações Coletivas nos Estados Unidos: O que podemos aprender com eles?. Salvador: JusPodivm, 2013.

SABEL, Charles F.; SIMON, William H. Destabilization rights: How public law litigation succeeds.Harvard Law Review., v. 117, p. 1016-1101, fev. 2004.

SCHLANGER, Margo. Beyond the hero judge: institutional reform litigation as litigation. Michigan Law Review, v. 97, n.6, p.1-44, 1999.

STURM, Susan P. A normative theory of public law remedies. Georgia Law Review, v. 79, n.8, p. 1355-1446, 1990.

STURM, Susan. The legacy and future of corrections litigation. University of Pennsylvania Law Review, v.142, n.2, p.641-735, dez.1993.

STURM, Susan. Resolving the remedial dilemma: Strategies of judicial intervention in prisons. University of Pennsylvania Law Review, v.138, n.3, p.807-910. jan.1990.

THEODORO JUNIOR, Humberto; NUNES, Dierle José Coelho; BAHIA, Alexandre Melo Franco. Litigância de interesse público e execução comparticipada de políticas públicas. Revista de Processo, v.4, n,23, p. 121-152, jun. 2013.

VENTURI, Elton. Processo Civil Coletivo: A tutela jurisdicional dos direitos difusos, coletivos e individuais homogêneos no Brasil - Perspectivas de um Código Brasileiro de Processos Coletivos. São Paulo: Malheiros Editores, 2007.

VERBIC, Francisco. El remedio estructural de la causa "Mendoza": Antecedentes, principales características y algunas cuestiones planteadas durante los primeros tres años de su implementación. Anais - Facultad de Ciencias Jurídicas y Sociales (U.N.L.P), v. 43, p. 267-286, $2013 . \quad$ Disponível em: <http://sedici.unlp.edu.ar/bitstream/handle/10915/33771/Documento_completo.pdf?s 
Rio de Janeiro. Ano 15. Volume 22. Número 1. Janeiro a Abril de 2021

Periódico Quadrimestral da Pós-Graduação Stricto Sensu em Direito Processual da UERJ

Patrono: José Carlos Barbosa Moreira (in mem.). ISSN 1982-7636. pp. 350-378

www.redp.uerj.br

equ ence=1>. Acesso em: 20 abr. 2020.

VIOLIN, Jordão.Holt v. Sarver e a reforma do sistema prisional no Arkansas. In: ARENHART, Sérgio Cruz; JOBIM, Marco Félix (org.). Processos estruturais. Salvador: JusPodivm, 2017, p.303-353. 